\title{
The Prediction of Social Problem-Solving Skills Based on Birth Order and Attachment Styles
}

\author{
Khadijeh Abolmaali $^{1 *}$, Leila Keivan ${ }^{2}$, Bita Ajilchi ${ }^{3}$ \\ ${ }^{1}$ Assistant Professor of Educational Psychology, Roudehen Branch, Islamic Azad University, Tehran, Iran \\ ${ }^{2}$ MA in General Psychology, Science and Research Branch, Islamic Azad University, Tehran, Iran \\ ${ }^{3}$ Department of Psychology, Faculty of Human Science, Science and Research Branch University, Islamic Azad \\ University (IAU), Tehran, Iran \\ Email: *Sama.abolmaali@gmail.com
}

Received December 2 ${ }^{\text {nd }}, 2013$; revised January $2^{\text {nd }}$, 2014; accepted January $9^{\text {th }}, 2014$

Copyright (C) 2014 Khadijeh Abolmaali et al. This is an open access article distributed under the Creative Commons Attribution License, which permits unrestricted use, distribution, and reproduction in any medium, provided the original work is properly cited. In accordance of the Creative Commons Attribution License all Copyrights (c) 2014 are reserved for SCIRP and the owner of the intellectual property Khadijeh Abolmaali et al. All Copyright (c) 2014 are guarded by law and by SCIRP as a guardian.

\begin{abstract}
The purpose of this research was to predict social problem-solving skills in two dimensions (functional and dysfunctional), based on birth order and attachment styles in university students. For the study, 234 students were randomly selected at Azad University in the Science \& Research Branch, who completed two questionnaires: Hazen \& Shaver's Attachment Styles Inventory (AAI) and D'Zurilla et al.'s Social Problem Solving Skills Inventory-Revised (SPSI_R). Data were analyzed with multiple regression and MANOVA tests. The results revealed that avoidant and anxious attachment styles had significant and positive relationship with dysfunctional social problem solving, and had significant and negative relationship with functional social problem solving skills; and birth order significantly predicted dysfunctional social problem solving. Also, a comparison of the first and last children showed that a significant difference existed between the mean of first and last children in avoidant attachment style (first children were higher than that of last children). But there is no significant difference between first and last children in the dimensions of social problem-solving skills.
\end{abstract}

Keywords: Social Problem-Solving Skills; Attachment Styles; Birth Order

\section{Introduction}

During history, psychologists, philosophers and educational practitioners have stated that the ability to solve problems is one of the most crucial issues related to humankind's welfare. Social problem solving is the process by which people attempt to identify or discover effective or functional solutions to problems that they experience in everyday living. Good or effective problem solvers are likely to function more competently and experience less psychological distress when encountering difficult or stressful problems as compared to poor or ineffective problem solvers (D’Zurilla, Nezu, \& Maydeu-Olivares, 2002: p. 1). Social problem solving (SPS) is a cognitive-behavioral process and is a synonym for coping with stress and interpersonal communication. In D'Zurilla et al.'s model, SPS is measured in 5 scales: Positive Problem Orientation (PPO), Negative Problem Orientation (NPO), Rational Problem Solving (RPS), Impulsivity/Carelessness Style (ICS) and Avoidant Style (AS) (Chang, D’Zurilla, \& Sanna, 2004). PPO and RPS are effective problem-solving mechanisms and AS, ICS and NPO are ineffective or poor problem-solving mechanisms. PPO is a constructive problem-solving cognitive set that involves the general disposition to: appraise a problem as a "challenge", believe that problems are solvable (“optimism”), believe in one's per-

${ }^{*}$ Corresponding author. sonal ability to solve problems successfully (believe that successful problem solving takes time and effort), and commit oneself to solving problems with dispatch rather than avoiding them. In contrast, NPO is a dysfunctional or inhibitive cognitive-emotional set that involves the general tendency to view a problem as a significant threat to well-being, to doubt one's own personal ability to solve problems successfully, and to become easily frustrated and upset when confronted with problems. RPS is a constructive problem-solving style that is defined as the rational, deliberate, and systematic application of effective problem-solving skills. IPS is a dysfunctional problem-solving pattern characterized by active attempts to apply problem-solving strategies and techniques, but these attempts are narrow, impulsive, careless, hurried, and incomplete (D'Zurilla et al., 2002).

AS is another dysfunctional problem-solving pattern characterized by procrastination, passivity or inaction and dependency. The avoidant problem solver prefers to avoid problems rather than confront them head on, puts off problem solving as long as possible, waits for problems to resolve themselves, and attempts to shift the responsibility for solving his or her problems to other people (Chang et al., 2004: p. 15). Undoubtedly, one of the most important changes in modern and contemporary psychology fields is the development of the Bowlby Attachment Theory; attachment is an emotional bond to another person and 
is used to describe a special kind of relationship between two people, which can be referred as a type of "affection bond", for example, a baby seeks closeness to someone. This has a great role in the emotional development of children. According to the Bowlby theory, the process of attachment is one of the most vital prerequisites for effective development (Ghorbani, 2002). Ainsworth et al. (1978) described three major styles of attachment: secure attachment, ambivalent-insecure attachment, and avoidant-insecure attachment. Later, Main and Solomon (1986) proposed that inconsistent behavior on the part of parents might be a contributing factor in this style of attachment. In later research, Main and Hesse (1990) argued that parents who acted as figures of both fear and reassurance to a child contributed to a disorganized attachment style. Because the child feels both comforted and frightened by the parents' confusion results.

People with a secure attachment style have a considerable difference in their approach to overcoming problems in comparison with people with anxiety or avoidant attachment styles. Based on their theory, secure people show little sign of mental problems when they are faced with problems. The experience of a secure and supportive relationship with the mother in childhood makes people more secure and enables them to achieve high potential self-confidence resources in this regard. These people will be more able to accept personal and social responsibilities because they are more able to contend with hard situations and problems. They can also find better solutions for their pitfalls (Gillath, Mikulincher, \& Shaver, 2001). Fullam (2002) also stated that people with secure attachments acted better in their interpersonal relations, solving social problems, challenging tensions, and controlling their excitement better than people with insecure attachment. These people also tended to have better physical and spiritual health as well. The impact of attachment on cognitive processes has a relationship with the quality and quantity of a person's received stimulants. In fact, secure children discover that their environment is secure in comparison with insecure ones. The degree of received information and stimulants in these children is higher than that in insecure children and this makes them able to apply high-potential verbal, imaginary and communicative skills (Vermigli \& Toni, 2004).

The link between secure and fearful attachment, and social loneliness was mediated, in part, by social skills (DiTommaso, Barnnen-McNulty, Ross, \& Burgess, 2003).

\section{Related Literature}

Allen (2002) showed that the students' adjustment had a positive relationship with the attachment style of adults and the relationship between insecure attachments was negative with social adjustment. He showed that secure attachment was a significant predictor for the students' social problem-solving skills. Vafaeian (2006) carried out a study of the relationship between social skills and students' attachment styles and showed that there was a significance relationship between their attachment styles and social skills; in other words, when the scores of the students in the secure style were increased, it influenced their social skills. On the other hand, increasing the avoidant and ambivalent style scores reduced the social skills. Besharat \& Shalchi (2007) emphasized the significant relationship between attachment styles and stress-coping mechanisms. They concluded that there was a relationship between secure attachment styles with emotional strategies for coping with stress. Kobak, et al. (1993) showed that there was a positive relationship between insecure attachment and the ability to problem-solve and the experience of anger. Another research paper, with the aim of studying the relationship between attachment styles and stress-coping strategies with anger control among the students, indicated that there was a direct relationship between problembased stress coping strategy and secure attachment, and emotional coping stress with insecure attachment (Rafiee-Tari, 2008). Alfred Adler, an Australian psychologist and contemporary with Sigmund Freud and Karl Yong, stated that birth order influenced people's personalities. Because the birth order causes children to have different attitudes towards their parents, they will have different childhood situations assisting in their personality formation. Adler (cited in Harris, 2006) stated that birth order had a positive impact on lifestyle. The results of a study by Zaeri (2003) had the aim of the determination of group acceptance relationships and social skills with birth order among high school students, and showed that there was no relationship between the social skills of young people according to birth order. Also, another study stated that birth order did not impact on social skill dimensions (Riggio \& Sotoodeh, 1989).

The main question of this study is whether social problemsolving skills can be predicted by birth order and attachment styles in adults.

Research hypotheses are:

1) The birth order and attachment styles can predict social problem-solving in two dimensions of functional and dysfunctional styles.

2) There is a significant difference between attachment styles and social problem-solving skills of the first and last child.

\section{Method}

\section{Procedure}

The method of this research is descriptive. The statistical population included the whole student population of Tehran's Research and Science University during 2012-2013. The sample was randomly selected by a cluster method. The study involved 155 girls and 234 boys.

\section{Instruments}

\section{Adults’ Attachment Styles Inventory: (AAI)}

This questionnaire was devised by Hazen and Shaver (1987) and has been used in Iran on the nurses of governmental hospitals of Isfahan City (Rahimian et al., 2006). This questionnaire was a self-report scale, which included 15 items. The scoring of the test was based on the Likert scale from never (0) to fairly always (4). The scores of the sub-scale attachment were obtained by the mean five questions in every sub-scale of the test, as follows: To determine the attachment style of every person, the digit values of the choices related to every level were summed together and then divided by 5 in this case. The subjects were asked to choose questions defining their traits better in this regard. The explanatory factor analysis of this questionnaire was carried out by Collins and Read (1990) and three factors of attachment were extracted in this case.

\section{Short Form of Social Problem-Solving Revised Version: (SPSI-R)}

In order to evaluate the ability of the participants' social 
problem-solving skills, a short form of 25 questions devised by D’Zurilla, Nezu and Mydieu-Elivares standardized by Taghilou (2009) was applied in this case. This questionnaire had five sub-scales, these sub-scales are: Positive orientation towards the problem, Negative orientation towards the problem, rational problem-solving style, Avoidant style and Impulsivity-carelessness styles. The whole coefficients of the above mentioned items were as follows, respectively: $0.68,0.75,0.62,0.68$, and 0.68 . The total coefficients obtained for the related tool were 0.69. In addition, after processing the model from the confirmed factorial analysis, the indices of processing were obtained at suitable levels for the related test (Taghilou, 2009) Three scales were for the inefficient or non-functional methods in relation to the avoidant style and Impulsivity-carelessness style affairs and two scales were subjected to the efficient or functional methods of the positive orientation in terms of the problem-solving process (Abolmaali, 2010).

\section{Findings}

In Table 1 descriptive indices of studying variables were reported.

According to the above table, it can be stated that all of the variables tended to normal distribution, due to skewness and kurtosis which were between -1 and +1 .

First hypothesis: Birth order and attachment styles (avoidant, anxious and secure) can predict social problem solving (in 2 dimensions: functional and non-functional) in students of the university.

For the testing of this hypothesis in this research, multiple regression analysis with a stepwise method was used.

According to Table 2, the $\beta$ coefficient showed that avoidant and anxious styles have significantly negative relationships with functional social problem solving, whereas avoidant and anxious styles have significantly positive relationships with dysfunctional social problem solving. Also, birth order significantly predict dysfunctional social problem solving, so that in first children dysfunctional social problem solving, more than last children.

Second hypothesis: there is a significant difference between first and last children in attachment styles.

For consideration of this hypothesis, firstly the assumptions of MANOVA were evaluated, such as homogeneity of variance and covariance and homogeneity of slope of regression line, and then MANOVA was used for analysis of the data.

As shown in Table 3, because value of Wilk's Lambada (0.980) and value of $F=1.843$, it could be said that the effect of the group on the social problem solving and attachment styles is not significant and it can be stated that the difference of the combination of dependent variables in the groups is not significant. As a result, there is no significant difference between combination of components of attachment styles in first and last children. The results of the test between subject effects for the evaluation of the effect of each dependent variable are given separately in Table 4.

As shown in Table 4, the between-groups tests showed that differences in avoidant skills are significant $(\operatorname{sig}<0.05)$ and the mean scores in the first children were more than last children.

The third hypothesis was that there is a significant difference between first and last children in social problem-solving skills.

For consideration of this hypothesis, firstly the assumptions of MANOVA were evaluated, such as the homogeneity of va-
Table 1.

The descriptive indices of attachement styles and social problem solving.

\begin{tabular}{ccccc}
\hline \multirow{2}{*}{ Variables } & \multicolumn{4}{c}{ Descriptive Indices of variables } \\
\cline { 2 - 5 } & Mean & $\begin{array}{c}\text { Standard } \\
\text { Deviation }\end{array}$ & Skewness & kurtosis \\
\hline Secure attachment style & 3.29 & 0.592 & -0.041 & -0.027 \\
Avoidant attachment style & 2.73 & 0.715 & 0.214 & 0.068 \\
Anxious attachment style & 2.62 & 0.733 & 0.163 & -0.562 \\
$\begin{array}{c}\text { Functional social } \\
\text { problem solving }\end{array}$ & 3.50 & 0.649 & -0.286 & -0.143 \\
$\begin{array}{c}\text { Dysfunctional social } \\
\text { problem solving }\end{array}$ & 2.24 & 0.583 & 0.635 & 0.278 \\
\hline
\end{tabular}

Table 2.

Summery of regression analysis for prediction of social problem solving (functional and disfunctional) based on attachement styles (avoidant, anxious and secure) and birth order.

\begin{tabular}{cccccc}
\hline \multirow{2}{*}{ Variables } & \multicolumn{5}{c}{ prediction of social problem solving based on attachment } \\
\cline { 2 - 6 } & Sps $^{\mathrm{a}}$ & $\mathrm{B}$ & $\beta$ & $\mathrm{t}$ & $\mathrm{sig}$ \\
\hline \multirow{2}{*}{ Constant } & functional & 1.761 & - & 4.62 & 0.000 \\
& dysfunctional & 1.158 & - & 4.92 & 0.000 \\
Secure style & functional & 0.063 & 0.062 & 0.0764 & 0.446 \\
& dysfunctional & 0.036 & 0.037 & 0.572 & 0.568 \\
Avoidante & functional & -0.181 & -0.150 & -1.999 & 0.046 \\
style & dysfunctional & 0.108 & 0.138 & 2.005 & 0.042 \\
Anxious style & functional & -0.144 & -0.173 & -2.107 & 0.037 \\
& dysfunctional & 0.213 & 0.276 & 4.426 & 0.000 \\
Birth order & functional & 0.010 & 0.008 & 0.107 & 0.915 \\
& dysfunctional & 0.139 & 0.131 & 1.993 & 0.048 \\
\hline
\end{tabular}

${ }^{\mathrm{a}}$ social problem solving. functional SPSS $\left\{\mathrm{R}=0.210 ; \mathrm{R}^{2}=0.044\right.$; adjusted $\mathrm{R}^{2}=$ $\left.0.034 ; \mathrm{F}=4.3333^{* *} \mathrm{P}<0.05,{ }^{* *} ; P<0.01\right\}$. dysfunctional SPSS $\left\{\mathrm{R}=0.315 ; \mathrm{R}^{2}=\right.$ 0.099; adjusted $\left.\mathrm{R}^{2}=0.090 ; \mathrm{F}=10.55^{* *} P<0.05,{ }^{* *} ; P<0.01\right\}$.

Table 3.

Multivariate test.

\begin{tabular}{ccccccc}
\hline \multirow{2}{*}{ effects } & \multicolumn{6}{c}{ Wilk's Lamda test } \\
\cline { 2 - 7 } & value & F & df & df of error & sig & size effect \\
\hline sex & 0.980 & 1.843 & 3 & 273 & 0.140 & 0.020 \\
\hline
\end{tabular}

Table 4.

Between subjects effects.

\begin{tabular}{ccccccc}
\hline \multirow{2}{*}{ source } & \multicolumn{7}{c}{ Between subjects effects } \\
\cline { 2 - 7 } & $\begin{array}{c}\text { Dependent } \\
\text { variable }\end{array}$ & $\mathrm{Ss}$ & $\mathrm{df}_{1}$ & $\mathrm{df}_{2}$ & $\mathrm{MS}$ & $\mathrm{F}$ \\
\hline Birth & Avoidant style & 2.321 & 1 & 275 & 2.32 & ${ }^{*} 4.62$ \\
order & Secure t style & 0.08 & 1 & 275 & 0.08 & 0.225 \\
& Anxious style & 0.144 & 1 & 275 & 0.144 & 0.253 \\
\hline
\end{tabular}

riance and covariance, and homogeneity of slope of regression line, and then MANOVA was used for data analysis. 
As shown in Table 5, because the significance levels related to tests of MANOVA (Wilk's Lambda $=0.981, \mathrm{~F}=2.648$ and $p$ $=0.073$ ) it can be said that the effect of the group on social problem solving is not significant and it can be stated that the difference between the combination of components of social problem solving in groups is not significant. As a result, there is no significant difference between components of social problem-solving skills in the first and last children. The results test of between subjects effects for the evaluation the effect of each dependent variable are given separately in Table 6 .

As shown in Table 6, the between-groups differences in functional and dysfunctional social problem solving are not significant (sig $>0.05$ ) and the mean scores in the first and last children are not significant.

\section{Discussion}

The findings of the present study showed that avoidant and anxious attachment styles had significant and positive relationship with dysfunctional social problem solving, and had significant and negative relationship with functional social problem solving skills. The results are consistent with that of Besharat \& Shalchi (2007), Rafiee-Tari (2008) and Kobak, et al. (1993).

Also results revealed that differences in avoidant attachment styles in first and last children were significant, so that in the first children means of avoidant attachment style were more than last children; and differences in functional and dysfunctional social problem solving were not significant in the first and last children. Besharat \& Shalchi (2007) emphasized on the significant relationship between attachment styles and stress-coping mechanisms.

The obtained results of the present study are consistent with the studies carried out by Kobak et al. (1993) and Rafiee Tari (2008). It seems that the insecure attachment style can cause the formation of weak communicative skills, making inefficient social problem-solving skills. In other words, they will have weak social cognition in this regard. Social cognition requires social information regarding the most accurate processing in this case because it should be able to respond to the requirements in this related setting (Abolmaali, 2010). Hence, people with insecure attachment styles will have weak social problemsolving skills.

The results of the present study show that there is a difference between the first and last offspring in terms of avoidant attachment styles; in other words, the first offspring often uses the avoidant method. The results of the research can be consistent with the viewpoints of Adler who believed that the first offspring often felt the changes in their own establishment in the family. Some research findings show that the older children are usually susceptible to anxiety and this may reflect the lack of experience and confidence among these people and parents (Karimi, 2003). This lack of experience in the mothers may be the first essential reason why the insecure attachment style may be formed among children in this regard.

Also, the results showed that there was no obvious difference between the first and last offspring in terms of the social problem-solving skills variables. The findings of the study are consistent with research of Zaeri (2003), Riggio and Sotoodeh's (1989). It can be said that due to, on the one hand, the importance of the exciting experiences of childhood in the formation of excitement, and on the other hand, increased statistics of life problems, it is suggested that educational courses could be very
Table 5.

Multivariate test.

\begin{tabular}{ccccccc}
\hline \multirow{2}{*}{ effects } & \multicolumn{6}{c}{ Wilk’s Lamda test } \\
\cline { 2 - 7 } & value & F & df & df of error & sig & size effect \\
\hline sex & 0.981 & 2.648 & 2 & 247 & 0.073 & 0.019 \\
\hline
\end{tabular}

Table 6.

Between subjects effects.

\begin{tabular}{ccccccc}
\hline \multirow{2}{*}{ source } & \multicolumn{7}{c}{ Between subjects effects } \\
\cline { 2 - 7 } & $\begin{array}{c}\text { Dependent } \\
\text { variable }\end{array}$ & Ss & $\mathrm{df}_{1}$ & $\mathrm{df}_{2}$ & $\mathrm{MS}$ & $\mathrm{F}$ \\
\hline Birth & Functional & 0.557 & 1 & 275 & 0.557 & 1.227 \\
order & Dysfunctional & 0.838 & & 275 & 0.838 & 2.359 \\
\hline
\end{tabular}

effective for mothers to enable awareness of their role in nurturing their children to promote healthy attachment styles. This will help mothers to improve their interaction skills with their children and help their children to be secure in their attachment to them.

\section{REFERENCES}

Abolmaali, Kh. (2010). Theories of criminology and delinquency. Tehran: Arjmand.

Ainsworth, M. S., Blehar, M. C., Water, E., \& Wall, S. (1978). Patterns of attachment: Psychological study of the strange situation. Tilsdate, NJ: Elbaum.

Allen, J. P. (2002). Attachment and autonomy as predictors of the development of social skills and deviance during mid-adolescence. Journal of Consulting and Clinical Psychology, 70, 56-66. http://dx.doi.org/10.1037/0022-006X.70.1.56

Besharat, M. A., \& Shalchi, B. (2007). The relationship between attachment styles and coping stress mechanism. Journal of Iranians' Psychologists, 11, 225-235.

Chang, C., D’Zurilla, T. J., \& Sanna, L. (2004). Social problem solving: Theory, Research, and Training. Washington DC: American Psychological Association. http://dx.doi.org/10.1037/10805-000

Collins, N. L., \& Read, S. J. (1990). Adult attachment, working models, and relationship quality in dating couples. Journal of Personality and Social Psychology, 58, 644-663. http://dx.doi.org/10.1037/0022-3514.58.4.644

Ditommaso, E., Brannen-McNulty, C., Ross, L., \& Burgess, M. (2003). Attachment styles, social skills and loneliness in young adults. Journal of Personality and Individual Differences, 35, 303-312. http://dx.doi.org/10.1016/S0191-8869(02)00190-3

D’Zurilla, T. J., Nezu, A. M., \& Maydeu-Olivares, T. (2002). Social Problem-Solving Inventory Revised (SPSI-R): Manual. North Tonawanda, NY: Multi-Health Systems.

Fullam, A. (2002). Adult attachment, emotional intelligence, health, and immunological responsiveness to stress. Dissertation Abstracts International: Section B: The Sciences an Engineering, 63, 1079.

Gillath, O., Mikulincer, M., \& Shaver, P. (2001). Subliminal 7 threatprimes increase the accessibility of attachment figures 7 names. Poster Presented at the Annual Meeting of the American Psychological Association, San Francisco, CA.

Ghorbani, N. (2002). Short-term Dynamic Psychotherapy. Tehran: Samt.

Karimi, J. (2003). Personality psychology (9th edition). Tehran: Payam Noor University Press.

Harris, J. R. (2006). No two alike. Journal of Human Nature and Human Individuality, 30, 107-112.

Hazen, C., \& Shaver, P. (1987). Romantic love conceptualizes easy attachment process. Journal of Social Psychology, 52, 511-524. http://dx.doi.org/10.2307/1131448 


\section{K. ABOLMAALI ET AL.}

Kobak, R. R., Holland, E. C., Rayanne, F., William, S. F., \& Wendy, G. (1993). Attachment and emotion regulation during mother-teen problem solving: A control theory analysis. Journal of Child Development, 64, 231-245.

Main, M., \& Hesse, E. (1990). Parents' unresolved traumatic experiences are related to infant disorganized attachment status: Is frightened/frightening parental behavior the linking mechanism? In M. T. Greenberg, D. Cicchetti, \& E. M. Cummings (Eds.), Attachment in the preschool years: Theory, research, and intervention (pp. 161182). Chicago, IL: University of Chicago Press.

Main, M., \& Solomon, J. (1986). Discovery of an insecure-disorganized/disoriented attachment pattern: Procedures, findings and implications for the classification of behavior. In T. B. Brazelton, \& M. Yogman (Eds.), Affective development in infancy (pp. 95-124). Norwood, NJ: Ablex.

Nezu, M. C., D’Zurilla, T. J., \& Nezu, A. M. (2005). Problem solving therapy: Theory, practice and application to sex offenders. In M. McMurran, \& J. McGuire (Eds.), Social problem solving and offending: Evidence, evaluation and evolution (pp. 103-123). Chichester: John Willy \& Sons, Ltd. http://dx.doi.org/10.1002/9780470713488.ch6

Rahimian, A., Asghar Nejad, F., \& Rahimi Nejad, A. S. (2006). Rela- tionship between attachment style and mental health in adults in earthquake struck the city of Bam. Journal of Cognitive Studies, 11, 23-28.

Rafiee Tari, N. (2008). Attachment styles, coping with relational aggression in students. MS Thesis, Islamic Azad University, Central Tehran Branch.

Riggio, R. E., \& Sotoodeh, Y. (1989). Social skills and birth order. Fullerton: California State.

Taghiloo, S. (2009). Structural equation modeling approach in examining the relationship between personality traits, social problem solving in girls and boys. PhD Dissertation, Islamic Azad University, Central Tehran Branch.

Vafaeian, M. (2006). The relationship between attachment styles and social skills in high school students in Yazd. MS Thesis, Yazd University.

Vermigli, P., \& Toni, A. (2004). Attachment and field dependence: individual differences in information processing. Journal of European Psychologist, 9, 43-55. http://dx.doi.org/10.1027/1016-9040.9.1.43

Zaeri, M. (2003). Relationship between birth order, social skills and group acceptance among male students school. MS Thesis, Islamic Azad University, Roudehen Branch. 